\title{
A MODERNIDADE E SEUS IMPACTOS NA CRÍTICA DO DIREITO PENAL
}

THE MODERNITY AND ITS IMPACTS IN THE CRIMINAL $L A W^{\prime} S$ CRITICS

\author{
Ruth Maria Chittó Gauer ${ }^{1}$ \\ $\mathrm{PUC} / \mathrm{RS}$
}

\section{Resumo}

A noção de verdade e os paradigmas decorrentes da modernidade, construídos em função do conceito de ciência, tem reflexos substanciais no direito penal. Assim, decorrem da modernidade conceitos cultivados na ciência penal atual, os quais não se sustentam no estágio atual do desenvolvimento da teoria do conhecimento.

\section{Palavras-chaves}

Modernidade. Paradigmas. Direito Penal. Crítica.

\section{Abstract}

The concept of True and the standards born in the modern age have substantial influence into the criminal law. Thus, it is from the modernity some concepts used in the actual criminal science, but they are unable to be used as says the actual theory of knowledge.

Keywords

Modernity. Standards. Criminal law. Critics

\section{I - Introdução}

As premissas que embasaram a ciência do direito devem muito à modernidade. $\mathrm{O}$ processo de secularização e o racionalismo daquela época fizeram com que o direito fosse influenciado pelos seus paradigmas. Outrossim, para conhecer a modernidade, caminho eficaz é, como afirmou Foucault, recorrer ao direito penal. O direito

\footnotetext{
${ }^{1}$ Coordenadora do Programa de Pós-graduação da PUC/RS
} 
penal está substancialmente ligado à política e ao pensamento daquele período, sendo o crime tido como uma ofensa direta ao corpo do rei, enquanto o carrasco que executava a pena era visto como a longa manus do soberano, o qual reagia à violação do seu corpo².

As citadas premissas da ciência moderna, que serviram como pressupostos para o direito penal - e para a ciência do direito - são a experimentação, a objetividade, a neutralidade e a generalização. Essas premissas se complementam e demarcam o conhecimento construído, qualificado por seus artífices como "científico". Ressaltese que a experimentação trouxe a primazia da técnica e a objetividade sustentou o discurso da neutralidade do cientista. As humanidades em geral, assim como as ciências sociais aplicadas, buscaram para si o caráter científico. Durante três séculos foram aplicadas em diferentes campos do saber, instituindo o sujeito da modernidade. A dicotomia sujeito/objeto, própria da modernidade, é resultado dessa premissa, separou ciência e política, ciência e direito, assim como todos os campos de saber e instalou, em certo sentido, o conservadorismo.

A ciência jurídica se estruturou a partir da secularização. $O$ princípio secularizador, portanto, constitui-se no elemento estruturador das sociedades ocidentais, através do seu direito. O direito enquanto elemento estruturador vai reivindicar para si a noção moderna de verdade, o que será dramático na seara do direito penal. Esta verdade moderna, excessiva por natureza, tem suas marcas no direito penal até hoje sentidas. Isto se dá porque o direito penal continua usando a premissa da evidência dos fatos, a qual enfatize-se - é uma herança do conceito moderno de verdade. A

\footnotetext{
${ }^{2}$ FOUCAULT, Michel. Vigiar e punir. Petrópolis, Vozes, 1998.
} 
evidência, como diz Rui Cunha Martins ${ }^{3}$ é uma alucinação dos sentidos. Isto se dá por conta da argumentação. Note-se que em toda a argumentação, realizada em qualquer âmbito (não somente no direito penal!), a pratica utilizada é a extirpação das informações que impeçam a explicitação daqueles elementos que poderiam conotar um problema para o convencimento do que se quer que seja tido como verdade. Mesmo os fatos mais evidentes, notórios, chamados no âmbito judiciário penal de flagrante delito, carregam uma nebulosidade que impede a dita evidência, tomada como transparência.

Note-se que a tradição jurídica tende a agir frente ao flagrante delito deslocando para o juiz a responsabilidade de julgar uma "verdade" tida como óbvia, através de sua neutralidade e imparcialidade. Esse sentido da racionalidade é um legado da modernidade e não se sustenta ante à crítica que é feita por meio da retórica e da argumentação jurídica-penal.

Pois bem, essa incongruência posta tem sua origem no pensamento moderno e na sua absorção pela história das ideias contemporâneas. Note-se que, contemporaneamente, o vocábulo moderno é uma palavra "talismã", utilizado não para identificar um pensamento de uma época historicamente distante, mas sim para indicar um objeto de vanguarda. Mas o fato é que aquela época histórica também gerou vicissitudes, as quais foram apontadas por muitos, dentre os quais destaca-se Vico. Nesse panorama, o objeto da presente investigação é compreender as características das ideias da modernidade e realizar o seu cotejamento crítico com o direito penal.

${ }^{3}$ MARTINS, Rui Cunha. Modos de Verdade. Revista de História e Teoria das Idéias. Instituto de História e Teoria das Idéias, Universidade de Coimbra, Coimbra Volume 23, 2002. P. 19-20. 


\section{II - A compreensão da modernidade}

O termo modernidade volta-se para a compreensão de uma época histórica que se estende do século XVI ao século XVIII. Este é um período muito longo para que pensemos em características uniformes; isto é, não há uma única "modernidade", existem "modernidades". Nesta época, instalou-se um fluxo continuo de trocas culturais, formando-se uma rede cada vez mais densa de comunicações, o que faz com que esse período, além de longo, seja também extremamente complexo.

O que unificou os tempos modernos foi o conceito de fluxo. Com efeito, o fluxo desorganizou a cosmovisão medieval, ao mesmo tempo em que se tornou o centro de gravidade do pensamento ocidental dessa época. Os séculos XV e XVI conheceram a expansão através das navegações, as quais modificaram profundamente a visão de mundo e todas as ações que organizavam a vida dos europeus da época. Foi o fluxo que acelerou o ritmo social e criou profundas inseguranças e desordens na vida em sociedade.

Do final do século XVII até meados dos oitocentos, a convicção na ciência atingiu o seu apogeu, chegando a ser ela a depositária da esperança humana de um mundo melhor. A época moderna foi marcada por uma sucessão de revoluções capitaneadas, v.g., por Copérnico, Galileu, Descarte, Newton. Estas revoluções criaram o espírito geométrico e trouxeram aos homens a consciência do seu poder sobre a natureza e a organização racional da sociedade. Elucidativo pensar que o movimento pictórico de maior ascendência naquele momento foi o realismo. Kant ${ }^{4}$ considerava o século XVIII uma época crítica e o conteúdo desta referida crítica foi o mais importante fator para se chegar ao

\footnotetext{
${ }^{4}$ KANT, Immanuel. Critica da razão prática. Lisboa, Edições 70, 1989. Passim.
} 
Iluminismo. $\mathrm{O}$ autor ${ }^{5}$ observava que se considerava "um iluminado, vivente em uma época iluminada onde era permitido fazer uso público da razão, (...) até então severamente restringido pela autoridade e pelo dogma. Descartes e Locke deram o substrato filosófico para a busca dos próprios poderes humanos pelos quais o homem poderia traçar o seu destino desvinculado da fé". O racionalismo de Descartes justifica o poder da razão de perceber o mundo através de ideias claras e distintas, Locke ${ }^{6}$ valoriza os sentidos e a experiência na elaboração do conhecimento. Diante da questão qual o valor do nosso conhecimento e o que é o conhecimento? Kant, para responder essas indagações, coloca a razão em um tribunal - e, como isso, pretendeu superar a dicotomia racionalismo-empirismo para julgar o que pode ser conhecido e que tipo de conhecimento não possui fundamento.

Desde o Renascimento houve uma luta continua contra a autoridade; somou-se a essa luta o advento da ciência introduzida por Galileu no século XVII, e esses dois eventos impulsionam o surgimento do novo homem, o homem construtor de seu destino, o artífice do futuro.

Baumer, analisando Diderot, Troeltsch, Hume e Becker, entre outros, refere que existem diferentes facetas caracterizando o Iluminismo. A maneira como Diderot percebeu a época das luzes foi como um tempo onde a filosofia faria uma "revolução" nos espíritos, já que os homens buscavam e empregavam leis da razão na "natureza”. Assim, "para Troeltsch o Iluminismo é a passagem do sobrenaturalístico-mítico-autoritário para o naturalístico-científico-

${ }^{5}$ Cf. BAUMER, Franklin L. O pensamento europeu moderno. Lisboa, Edições 70, 1997. P.97.

${ }^{6}$ Cf. TOUCHARD, Jean. História das idéias políticas. Lisboa, Publicações EuropaAmérica, 1970. P. 75-77. 
individualista, que tendo peculiaridades em cada país, deu um grande impulso no pensamento do século, já que, era complexo, crivado de dúvidas e divisões internas. Esta diversidade de modo algum esgotou o pensamento essencial e produtivo do século. A idade da felicidade ou da razão para Hume libertaria a razão da escravidão das paixões, porém a maioria dos filósofos da época, impuseram limites a razão, o que os diferenciou dos grandes racionalistas do século anterior" ${ }^{7}$. Para a maioria dos filósofos franceses a razão não poderia penetrar para além do mundo das aparências, mas poderia entender a natureza empírica e inferir leis gerais que controlassem a natureza humana.

Dentro deste controle está a Felicidade, obsessão da época, que vai contra o "ultramundanismo" cristão. Para chegar a este objetivo de felicidade, rejeita-se o luxo e o prazer "filosófico", chamando-se a atenção para as virtudes da simplicidade e do patriotismo.

Outra faceta importante do Iluminismo foi o Romantismo, que sendo forte como o próprio movimento das luzes ou como a Revolução Científica, trouxe consigo, em suas antíteses, uma reviravolta no pensamento da época. O século das luzes é também um tempo de continuidade e de mudanças. Estas últimas estão presentes no crescente aumento de consciência de que na história ocorrem mudanças mesmo nos modelos do passado. Baumer refere que Becker demonstrou que havia muito de ser no centro do pensamento e que neste tempo de Fé e Razão as pessoas não tenham que concordar com tudo (como a Igreja queria que fosse), já que, isto os deixava mais perto da idade média e não lhes traria o espírito da modernidade. “(...) O devir imediatamente tão evidente, se referia

7 BAUMER, Franklin L. O pensamento europeu moderno. Lisboa, Edições 70, 1997. P. 164. 
muito mais aos modelos intemporais, do que a alguns modelos venerados ${ }^{8 ”}$. Esta é uma época em que se desenvolvem novas formas para a classificação e comparação das artes e das ciências, o que remodela profundamente a maneira de pensar sobre as questões perenes, valorizando-se profundamente alguns campos do conhecimento.

Fracassadas as tentativas de unificar as artes e as ciências, Diderot e D'Alembert viram a impossibilidade de arranjar um sistema como pretendiam os racionalistas do século XVII, já que, existiam muitos aspectos a serem analisados na ordem geral do universo. Além disso, dentro deste "Labirinto da natureza" os enciclopedistas elegeram o esquema de Bacon ${ }^{9}$ para escrever a enciclopédia, isto é, submeteram tudo a três faculdades humanas: a memória, a imaginação e a razão. Ao reconhecerem as diversas maneira de analisar determinado aspecto da natureza, em seu perspectivismo, D'Alembert e Diderot ${ }^{10}$ remontam a ideia de Kant de que a unidade existe, mas na razão humana: não pode ser reconhecida na natureza. Assistiu-se, nesse período, a fortes mudanças e algumas permanências. A Teologia, antes rainha de todas as ciências (regina scientiarum) tornara-se "subordinada" à história e à filosofia. Entretanto, nunca se discutiu tanto sobre religião como nesse período, pois existiam posições para esclarecê-la ou para afastá-la. As questões do homem, da natureza, da sociedade e da história também ganharam importância. Desde o quattrocento não se discutia tanto

8 BAUMER, Franklin L. O pensamento europeu moderno. Lisboa, Edições 70, 1997. P. 166-183.

9 BACON, Francis. Novunm Organum. In Col. Os Pensadores. São Paulo, Abril Cultural, 1973. Passim.

10 TOUCHARD, Jean. História das idéias políticas. Lisboa, Publicações Europa-América, 1970. P. 75-77. 
sobre estes temas.

Isso tornava a filosofia novamente importante. Para os enciclopedistas a filosofia era a soma dos conhecimentos da razão humana que tinha utilidade, e poderia ser mais ativa para libertar o homem de sua condição. É importante esclarecer que esta é uma filosofia em um sentido mais popular, que atinge tanto à contemplação quanto à ação. "Este tipo de filosofia também incluía, frequentemente a filosofia naturalista, é certo, e esta filosofia naturalista permanecia como Kant observou, na condição mais florescente ${ }^{11}$ ". A Matemática, no entanto, sofreu várias críticas. Ora por raciocinar sem levar em conta a natureza, ora por ter o espírito geométrico a serviço das ciências sociais. Os enciclopedistas ajudaram as ciências sociais a não se basear no modelo geométrico, quando escreveram que estas ciências derivam de ramos da filosofia e da ética e não das "ciências da natureza". Bacon, entretanto, continuou a crer que a natureza vinha antes do homem no seu sistema. Assim, a ciência tinha um grande império no século das luzes, mas, não absorvia a filosofia moral e nem a filosofia política. Também não absorvia a Arte (principalmente a arte mecânica considerada benéfica para a sociedade). Por sua vez, as Belas Artes, mais independentes, davam prazer e exercitavam a imaginação, construindo, também a discussão inicial sobre a estética. A História, resultado do tempo e da memória tinha seu espaço na enciclopédia, mas era polêmica em relação à sua confiabilidade como conhecimento. Vico defendia a ideia de que a história era mais exata que as ciências da natureza (que só Deus poderia conhecer). Este filósofo, desprestigiado na época, argumentava que, sendo a história criada pelo homem, este poderia

11 BAUMER, Franklin L. O pensamento europeu moderno. Lisboa, Edições 70, 1997. P.170 
conhecê-la. Isto contribuiu para que a história passasse a ser comentada, pensada e escrita de várias maneiras, inclusive mais secularizada.

Assim, aceitando que o homem era o centro do universo e deglutindo a noção segundo a qual o universo deveria permanecer misterioso - para que se pudesse tentar conhecer o homem e o que ele fazia - é que os filósofos do século XVIII passam a perceber os limites do poder da cognição humana, bem como, a sua natureza, a política, sua história, etc. São nestes desdobramentos de ideias que ocorrem as mudanças de pensamento. As mudanças, segundo Voltaire, são percebidas porque se parte do pressuposto de que há um império do costume na natureza, o qual imprime princípios invariáveis, para que estes dêem uma certa unidade à história. Voltaire exaltava a política e a ciência inglesa pois, naquele país, existia liberdade religiosa e política, além de a ter criado Bacon para a ciência.

Nunca houve uma revolução tão radical, no sentido de que destruiu, em um espaço de tempo comparativamente pequeno, quase "todos" os ídolos que tinham sido construídos com tanto esmero, não só pelo medievo como também pelos tempos modernos. A antiga modernidade, inicialmente apoiada pelos modernos do século XVII, realizou profundas mudanças na imagem do mundo, mas deixaram virtualmente intactos alguns bastiões importantes do Ser. A "nova" modernidade, no entanto, afastou o Ser, deixando os homens sem pontos de referência e colocando-os à deriva em um mar infinito de devir.

A isto chamou-se de o triunfo do "Espirito do tempo"12. Esse

12 BAUMER, Franklin L. O pensamento europeu moderno. Lisboa, Edições 70, 1997. P.170 
espírito foca o aspecto dinâmico da realidade, levando as pessoas para um "êxtase de ação"; fazendo-as correr a velocidades cada vez maiores, não possibilitou a conquista de metas fixas, visto que a realidade era tida como um devir, uma história, um processo dialético sem fim. Essa doutrina do tempo é o produto da ciência, a filha instável do pensamento positivista. Ele também a encontrou presente na filosofia contemporânea, no mundo einsteniano, bergsoniano, na literatura e na arte, assim como entre historiadores e filósofos como Oswald Spengler, que inventou a frase "Mundo-como-história", ou seja, integralmente dinâmico e nunca estático.

\section{III - Reações às ideias modernas}

As reações ao pensamento moderno vieram com intensidade. Um dos opositores mais importantes foi Giambattista Vico ${ }^{13}$ (16681744). Nos séculos XV e XVI a Itália representou o centro hegemônico do pensamento na Europa. O humanismo renascentista e sua vasta produção em diversos campos do conhecimento estabeleceram um padrão imitado no restante do continente europeu. No entanto, esse papel de vanguarda cultural foi sendo comprometido pela decadência econômica das cidades italianas e pelo avanço da Contra-Reforma. A partir de meados do século XVI e, sobremaneira nos séculos XVII e XVIII, a Itália mergulharia no ostracismo cultural. Os novos centros do pensamento deslocaram-se para áreas reformadas, como França e Inglaterra. Vico insere-se dentro desse contexto histórico. Evidentemente, a posição marcadamente anticartesiana, assumida desde o início de sua

\footnotetext{
${ }^{13}$ VICO, Giambattista. Os Pensadores. Seleção, tradução e notas de Antônio Lázaro de Almeida Prado. São Paulo: Abril, 1974.
} 
frustrada carreira acadêmica, estava relacionada à condição periférica ocupada pela península italiana no desenvolvimento do pensamento europeu.

O posterior esquecimento a que foi relegado seu pensamento relacionava-se à sua posição anticartesiana e contrária ao Iluminismo. Sua crítica a pretensão iluminista de compreender a experiência humana à luz das ciências naturais e a valorização da mitologia e da poesia como fontes de conhecimento colocaram Vico em rota de colisão com aquela corrente de pensamento que se tornaria hegemônica nos séculos seguintes. Para o pensador, a filosofia deveria buscar compreender os produtos culturais humanos, não devendo se isolar em abstrações excessivas. A pretensão racionalista de submeter o conhecimento ao método matemático é desprovida de sentido, pois existem produtos humanos fundamentais, como a poesia e a história, não carecem de demonstração lógica, pois repousam no verossímil. Um aspecto essencial dessa posição é o caráter problemático assumido pela ideia de verdade, ou seja, a perda de seu atributo de certeza.

Dessa forma, Vico resgatou a história do limbo a que foi lançada pelo cartesianismo. A crença na existência de ideias inatas e a proposta de unidade metodológica, a partir do modelo matemático, formulada por Descartes, colocava a história no exílio, aproximandoa das fábulas e narrativas literárias que não produziam nenhum resultado.

Ao mesmo tempo, a diversidade aparece perante o modelo cartesiano como um incômodo a ser removido. Conforme afirmara: "a verdade é que, enquanto me preocupava em considerar os costumes de outros homens, pouco encontrava que me convencesse, pois percebia neles quase tanta diversidade quanto a que notara antes 
entre as opiniões dos filósofos"14. Dessa forma, o racionalismo teleológico cartesiano buscava, obsessivamente, uma unidade metodológica à qual a história não se adaptava. Esse ideal da unidade era repetidamente referido por Descartes: "Assim vê-se que os edifícios projetados e concluídos por um único arquiteto são habitualmente mais belos e harmônicos do que aqueles que muitos procuraram reformar, aproveitando velhas paredes construídas para outros fins"15

O filósofo napolitano Vico ${ }^{16}$ condenava o cartesianismo em seus três elementos fundamentais: o apelo à autoconsciência, contida no cogito, ergo sum; a crença de que a existência de Deus pode ser provada e, por fim, o princípio de que ideias claras e distintas, constituem o fundamento da verdade. Para Vico a verdade e o fato ou o verdadeiro e o feito se equivalem, isto é, a condição de ser capaz verdadeiramente de conhecer qualquer coisa, de compreendê-la como oposta à sua simples percepção, é que o próprio criador a tenha criado. O cogito é apenas a consciência do ser e não sua ciência. Assim o homem não conhece a causa do seu próprio ser, pois ele não se cria a si mesmo. Por outro lado, a ideia de que as proposições matemáticas, enquanto auto-evidência de ideias claras e distintas, são fundamentos da certeza, é inadmissível para Vico, uma vez que as verdades matemáticas fazem parte de um sistema produzido pelo próprio homem. Como afirmaria Collimgwood"17, "a noção de ideias

\footnotetext{
14 DESCARTES, Rene. Discurso do Método. Brasília: Editora Universidade de Brasília, 1981, p. 36.

15 DESCARTES, Rene,. o $p$ cit. p. 38.

16 VICO, Giambattista. Os Pensadores. Op. Cit.

17 COLLINGWOOD, R. G. A Idéia de História. Lisboa: Editorial Presença, s/d, p. 88,
} 
claras e distintas é completamente subjetiva, prova apenas a crença na verdade de quem as formulou".

À razão cartesiana Vico oferecia o engenho, faculdade de descobrir o verossímil e o novo; à crítica fundada na razão, o filósofo napolitano oferece a tópica, arte que disciplina e dirige os procedimentos inventivos do engenho. $O$ verossímil pode ser compreendido como uma verdade problemática, colocada entre o falso e o verdadeiro, mas desprovido de qualquer garantia infalível de verdade. $\mathrm{O}$ autor separou a história das ciências da natureza, pois "a ordem das ideias deve proceder conforme a ordem das coisas". Ao condenar a aplicação do método matemático às ciências humanas, o filósofo afirmou a possibilidade humana de conhecer a história, justamente por ser o homem produto desta. A reflexão do filósofo napolitano considerava, ainda, a história enquanto processo dentro do qual o homem se expressa na criação de instituições, leis, governos, instituições, sem o sentido tautológico de alcançar o progresso na acepção iluminista. $O$ passado enquanto passado interessa enquanto uma continuidade do desenvolvimento geral das sociedades humanas.

O estudo da história, segundo Vico, permite identificar a existência, em épocas diversas, de um "espírito geral" que reaparece em outros períodos, permitindo aproximações e comparações. Grosso modo, esse "espírito geral" poderia ser resumido nos seguintes termos: período heróico, período clássico e um período de exaustão no qual a decadência da cultura leva uma civilização à barbárie. No entanto, não estamos perante os esquematismos fixos de uma teoria da história ao estilo de Maquiavel, mas em um modelo em espiral, na qual as fases não se repetem. Assim sendo, o barbarismo, que assola as civilizações ciclicamente, diferencia-se de formas anteriores de 
barbárie que o antecederam. Essa renovação impede qualquer possibilidade de vaticínios por parte dos historiadores.

Essas ideias em relação ao conhecimento histórico demarcavam claramente a posição anticartesiana de Vico ${ }^{18}$. Este percebe uma unidade entre as coisas e as ideias, entre sujeito e objeto, isto é, entre o historiador e os homens que ele estuda. Essa harmonização permite uma dilatação do campo metodológico, uma vez que o desenvolvimento histórico podia ser compreendido a partir de fontes como o estudo linguístico, os mitos, os costumes, a literatura e a tradição. Estas, em seu desenvolvimento revelam as mais profundas raízes da experiência humana ao longo da história. $\mathrm{O}$ entendimento de que a mitologia e a poesia, por exemplo, constituiriam apenas expressões "artísticas" desprovidas de importância revela uma visão reducionista. Ao contrário, fábulas, mitos, lendas são formas de representação de verdades, diretamente relacionadas aos seus respectivos contextos históricos.

Entretanto, adverte o autor, uma vez que "esse mundo civil foi feito certamente pelos homens", a compreensão histórica necessitava perceber as "ordens universais", os costumes impostos através do "senso comum" às sociedades humanas. Essa percepção opera com um movimento de reinterpretação das tradições, levada à efeito pelo historiador. O passado não pode ser visto no presente, pois, segundo o filósofo, é essencial compreender os fenômenos humanos à luz de suas dimensões históricas, libertando-se de sistemas racionalistas e abstratos na busca dos aspectos mais concretos da história. Nessa perspectiva, o filósofo italiano critica o modelo contratualista hobbesiano. 
Nesse modelo teórico-metodológico, Vico abriu caminho para a confecção de uma teoria da história em um novo patamar, libertando-a da dependência das fontes escritas. Ao desprezo cartesiano pelas ciências humanas, Vico ofereceu um modelo teóricometodológico ao mesmo tempo crítico e construtivo. Deixemos que o pensamento do filósofo fale por si só.

Os axiomas contidos na obra Princípios de (Uma) Ciência Nova ${ }^{19}$, demonstram uma "Outra propriedade da mente humana é que os homens sempre que das coisas remotas e desconhecidas não podem fazer nenhuma ideia, avaliam-nas a partir das coisas deles conhecidas e antevistas. Os homens que não sabem a verdade das coisas procuram ater-se ao certo, a fim de que, não podendo satisfazer ao intelecto com a ciência, ao menos a vontade repouse sobre a consciência. A filosofia considera a razão, de que procede a ciência do verdadeiro; a filologia considera a autoridade do arbítrio humano, de que resulta a consciência do certo". Refere-se, aqui, à vaidade dos eruditos. $\mathrm{O}$ espírito acadêmico que move os historiadores tende a fazê-los crer que, no passado histórico, estão a dialogar com seus pares. Salvo em uma tentativa de reconstituição da história imanente do pensamento, a partir de personalidades, tal fato não ocorre. Os fatos demonstram que, na maioria das vezes, a proeminência de personalidades históricas não coincide com a reflexão históricofilosófica.

IV - Apreciação conclusiva

Muito embora tivessem ocorrido reações fortes e muito bem fundamentadas ao pensamento racionalista, tal como fora organizado pelos iluministas, o século XVIII foi o século das reformas 
universitárias, todas estruturadas com base no modelo teóricometodológico cartesiano. Era a crença no projeto que levaria ao progresso e à consequente criação do paraíso terreno.

O conhecimento da "nova" ciência foi equivalente a uma remodelação e a uma transformação do estatuto existencial e autoreflexivo do homem. Tal processo conduziu ao afastamento do próprio eixo, da centralidade e da fixidez medieval idealmente preestabelecida. Nesse sentido, as fronteiras do saber tornaram-se dinâmicas e plásticas, seria o fruto da observação. Assim, a "sombra" do mundo projetava-se sobre o sujeito, e este, por sua vez, "iluminava" sua mundanidade. O próprio termo Iluminismo conduz a essa reflexão. As mudanças aceleraram não apenas um repertório de transformações, mas correram paralelamente com as urgências que as tornaram ameaçadoras. Assim, a idéia de movimento, permitida pelos novos conhecimentos, foi compreendida como constituinte dos novos ritmos que caracterizaram o Iluminismo. A corrida moderna constituiu-se, assim, na eterna busca do controle, da normatização do projeto.

A crise intelectual instalada no XVI pôs em dúvida, tanto o macrocosmos como o microcosmo, o corpo político e o próprio conhecimento da época $\mathrm{O}$ quadro acima descrito demonstra que o surgimento de um desejo intenso de ultrapassar a desordem existente no mundo e no pensamento da época.. A resposta a essa crise foi dada por uma filosofia que ao mesmo tempo podia restaurar e reconciliar além de proporcionar princípios permanentes e universais. $\mathrm{O}$ pensamento do século XVII se propôs organizar a desordem ocasionada pelo fluxo dos séculos XV e XVI, buscou na verdade objetiva a condição de transcendência as meras certezas objetivas. $\mathrm{O}$ apelo à razão foi a solução encontrada, pois reuniu condições para impor regras e leis em tudo, desde a natureza, à sociedade e à arte. A 
natureza foi geometrizada mostrada em um equilíbrio harmonioso entre os elementos verticais e horizontais movidos por leis universais e intemporais.

Toda essa organização que pretendia superar a desordem criou condições para a instalação do projeto moderno que estava estruturado na ideia de progresso e deu abertura para o historicismo. A busca de uma nova ordem nasceu objetivando o controle de um mundo que se movimentava rapidamente e estava totalmente desorganizado. Nos diferentes momentos da modernidade esse desejo esteve presente. Hoje, sabemos que ele ainda povoa os espíritos menos avisados. A época moderna foi, portanto, marcada por uma sucessão de revoluções que instauraram no período o fluxo que ainda não foi concluído. Sob esse ponto de vista ainda podemos falar em modernidade hoje. As revoluções de Copérnico, Galileu, Descartes, Newton movimentaram o mundo, por um lado, por outro, criaram o espirito geométrico e trouxeram ao homem a consciência de seu poder sobre a natureza e para organizar a sociedade racionalmente. $\mathrm{O}$ apelo a racionalidade se tornou fonte de organização de controle e de explicação sobre o homem, a natureza, Deus e mesmo a história.

A partir dessas premissas podemos pensar a modernidade como um modo de civilização que estruturou as sociedades ocidentais e criou condições para a implantação de um saber científico capaz de controlar. A tradição científica criada no ocidente moderno sofreu transformações ao longo dos últimos dois séculos, porém elas não foram suficientes para eliminar os seus fundamentos básicos. Seriam os cientistas conservadores por terem mantido essa tradição? Para tentar responder essa questão faz-se necessário inicialmente dizer que conservadorismo vem do termo conservador: é aquele que tende a conservar. Em política o conservador é denominado como aquele que é favorável á situação vigente, opondo-se ás reformas ou 
mudanças radicais. Podemos lembrar ainda aquele que conserva a tradição, como exemplo os tradicionalistas, os fundamentalistas seriam todos conservadores.

No entanto faz-se necessário lembrar que as tradições desses campos do saber estão inseridas na ciência moderna assim como a prática jurídica, essas tradições dizem respeito ao domínio do conhecimento moderno, tal como foi construída a partir do século XVII. O paradigma moderno construiu os pilares da ciência jurídica que ainda sustenta a categoria fundante, o indivíduo construído a partir do direito natural moderno que deu possibilidade ao surgimento da impessoalidade e dos grandes códigos.

Há, neste contexto alguns problemas a serem enfrentados: a ciência moderna criou premissas e métodos vinculados a uma verdade totalizante. O conhecimento foi tido como absoluto, cabal, universal e eterno. As premissas que embasaram a ciência moderna e que serviram como pressupostos para o direito estão estruturadas na experimentação, objetividade, neutralidade e generalização. Essas premissas se complementam e demarcam um conhecimento científico. A experimentação trouxe a elevação da técnica, a objetividade sustentou o mito da neutralidade do cientista, assim como a do juiz. Não é por acaso que somos, via de regra, advertidos de que decisões sensatas provêm de uma cabeça fria e de que emoções e razão jamais se misturam. A perspectiva largamente difundida era de que existiam sistemas neurológicos diferentes para a razão e para a emoção. António Damásio ${ }^{20}$ sugere que certos aspectos do processo da emoção e do sentimento são indispensáveis para a racionalidade. As emoções e os sentimentos, juntamente com a oculta maquinaria

20 DAMÁSIO, António R. O Erro de Descartes. Portugal: Publicações EuropaAmérica ed., 21 edições, 2000. Passim. 
fisiológica que lhes está subjacente, auxiliam-nos na assustadora tarefa de fazer previsões relativamente a um futuro incerto e planejar as nossas ações de acordo com essas previsões. Todos sabem que as pesquisas com base na ciência moderna levaram os muitos avanços em todos os campos do saber, no entanto, as teorias desenvolvidas por Prigogini, e tantos outros, não atingiram a forma tradicional de pensar outros vários campos do conhecimento. O fim das certezas chegou ao campo da física, da matemática da neurociência entre outros, mas não chegou ainda no direito penal, pois se continua a utilizar esse ramo do direito de noções modernas como o é a evidência e a causalidade. Este último conceito, aliás, inaugura no Código Penal vigente (art. 13) a parte referente ao crime.

$\mathrm{O}$ século XX revelou que a garantia pretendida pelos paradigmas modernos foi desmontada pela realidade empírica divulgada em tempo real. A identidade polarizada, tal como analisada por Hall21, fruto da multiplicação, é "celebração móvel", e de transformação contínua nos sistemas culturais. Esses fatores levam ao tempo da insegurança, um tempo diferente do tempo da segurança, no qual prevalece o estado de direito. Entre tantas inseguranças temos a insegurança jurídica que nos aproxima ao estado de natureza. Esse mal endógeno da máquina jurídica precisa ser revertido. Para tanto se faz necessário equilibrar o tempo da promessa com o tempo de requestionamento. Impõe-se o imperativo de uma nova gestão pública onde o caráter problemático dos fins, dos meios e dos resultados possa conduzir a outros critérios de oportunidades. Ost ${ }^{22}$ refere que "o direito tradicional dá lugar ao direito excepcional e ao

HALL, Stuart. A identidade cultural na pós-modernidade. Rio de Janeiro: DP\&A, 1997. Passim.

22 OST, François. O tempo do direito. Lisboa, Piaget, 1999. 
homem vitimado inscrito e datado numa sociedade onde há um elevado nível de desordem simbólica". De modo geral, a violência, vista mais especificamente como criminalidade, deixa transparecer uma reivindicação de ordenamentos sociais mais justos. Como se sabe, o conceito de justo (conceito relativo, mas sempre dotado de valor) é eminentemente arbitrário e, por outro lado, denuncia a impotência do Estado, que não consegue cumprir o seu projeto. Já não se acredita no devir, portanto não se acredita no projeto, (muitas vezes mais anunciado que desejado) de unificar e equilibrar a sociedade. Esse é um problema geral para os governos atuais; se problema real ou ficção discursiva é outro assunto.

Frente a essa complexidade, novas questões se fazem presente. O tempo da segurança, do estado de direito já não está presente. Caminharíamos para uma insegurança que nos levaria a um estado de natureza? Sabemos que a insegurança jurídica é um mal endógeno da máquina jurídica. Qual seria o remédio, o dever ser jurídico? Há uma consciência que um fator de segurança importante é o equilíbrio do tempo da promessa com o tempo de requestionamento. Impõe-se o imperativo da gestão pública: o direito penal - e todo o direito apresenta características do requestionamento e da temporalidade, marcado pela racionalidade falível. Uma nova gestão implica a integração da incerteza e da indeterminação dos valores, a nova direção às condutas é vista como um problema a construir, essa gestão deve assumir o caráter problemático dos fins, dos meios e dos resultados. A produção normativa, vista como uma inversão temporal operacionaliza e dirige os critérios de oportunidade que resultam das condições "reais" dos contextos de implementação.

$\mathrm{O}$ direito deu lugar à relação frente a frente, gerando ora a comunhão, ora a violência, esta última maior característica do direito penal. Dessa forma ocorre a heterogeneidade do elo social. A 
flexibilidade das prestações e a precariedade dos empregos, bem como a duração dos códigos e das instituições dão lugar a um tempo que é percebido como em frangalhos, que deve ser (re) questionado a todo instante, impondo o imperativo de viver o dia-a-dia para todos os segmentos da sociedade. Um dos diagnósticos mais claros dessa crise é o declínio do político. Toda e qualquer forma de ilícito pode ser considerado um fenômeno complexo, e, portanto, impossível de ser explicado sob o olhar de uma só ciência penal com base na "verdade" absolutizada e na imparcialidade do julgador.

\section{Referências}

BAUMER, Franklin L. O pensamento europeu moderno. Lisboa, Edições 70, 1997.

COLLINGWOOD, R. G. A Idéia de História. Lisboa: Editorial Presença, s/d.

DAMÁSIO, António R. O Erro de Descartes. Portugal: Publicações Europa-América., 21ª edição, 2000.

DESCARTES, Rene. Discurso do Método. Brasília: Editora Universidade de Brasília, 1981.

FOUCAULT, Michel. Vigiar e punir. Petrópolis, Vozes, 1998.

HALL, Stuart. A identidade cultural na pós-modernidade. Rio de Janeiro: DP\&A, 1997.

KANT, Immanuel. Critica da razão prática. Lisboa, Edições 70, 1989. MARTINS, Rui Cunha. Modos de Verdade. Revista de História e Teoria das Idéias. Instituto de História e Teoria das Idéias, Universidade de Coimbra, Coimbra Volume 23, 2002. OST, François. O tempo do direito. Lisboa, Piaget, 1999. 
TOUCHARD, Jean. História das idéias políticas. Lisboa, Publicações Europa-América, 1970.

VICO, Giambattista. Os Pensadores. Seleção, tradução e notas de Antônio Lázaro de Almeida Prado. São Paulo: Abril, 1974. 